\title{
BMJ Open Perspectives of people with inherited retinal diseases on ocular gene therapy in Australia: protocol for a national survey
}

\author{
Heather G Mack (D) , ${ }^{1}$ Fred K Chen, ${ }^{2,3}$ John Grigg, ${ }^{4,5}$ Robyn Jamieson, ${ }^{6}$ \\ John De Roach, ${ }^{7}$ Fleur O'Hare, ${ }^{1,8}$ Alexis Ceecee Britten-Jones (1) , ${ }^{1}$ \\ Myra McGuinness (D) , Nicole Tindill, ${ }^{10}$ Lauren Ayton, ${ }^{1,8}$ Australian Ocular Gene \\ Therapy Group
}

To cite: Mack HG, Chen FK, Grigg J, et al. Perspectives of people with inherited retinal diseases on ocular gene therapy in Australia: protocol for a national survey. BMJ Open 2021;11:e048361. doi:10.1136/ bmjopen-2020-048361

- Prepublication history and additional supplemental material for this paper are available online. To view these files, please visit the journal online (http://dx.doi.org/10.1136/ bmjopen-2020-048361)

Received 26 December 2020 Accepted 08 June 2021

Check for updates

(C) Author(s) (or their employer(s)) 2021. Re-use permitted under CC BY-NC. No commercial re-use. See rights and permissions. Published by BMJ.

For numbered affiliations see end of article.

Correspondence to A/Prof Heather G Mack; hmack@eyesurgery.com.au

\section{ABSTRACT}

Introduction Voretigene neparvovec-rzyl (Luxturna) was approved by the Australian Therapeutic Goods Administration on 4 August 2020 for the treatment of biallelic mutations in the RPE65 gene, a rare cause of congenital and adult-onset retinal dystrophy (predominantly Leber congenital amaurosis). Previous studies have shown that individuals who might participate in gene therapy trials overestimate clinical effect and underestimate risks. However, little is known about the perspectives of patients who may be offered approved gene therapy treatment for ocular conditions (as distinct from participating in clinical trials of gene therapy). The main objective of this study is to develop a tool to assess knowledge, attitudes and perceptions of approved and future genetic therapies among potential recipients of ocular gene therapy. In addition, we aim to assess the quality of life, attitudes towards clinical trials and visionrelated quality of life among this cohort.

Methods and analysis A new 'Attitudes to Gene Therapy for the Eye' tool will be developed following consultation with people with inherited retinal disease (IRD) and content matter experts. Australians with IRD or their guardians will be asked to complete an internet-based survey comprising existing quality of life and visual function instruments and items for the newly proposed tool. We expect to recruit 500 survey participants from patient support groups, the practices of Australian ophthalmologists who are specialists in IRD and Australian ophthalmic research institutions. Launch is anticipated early 2021. Responses will be analysed using item response theory methodology. Ethics and dissemination This study has received ethics approval from the University of Melbourne (\#2057534). The results of the study will be published in a peer-reviewed journal and will be presented at relevant conferences. Organisations involved in recruitment, and the Patient Engagement Advisory committee will assist the research team with dissemination of the study outcomes.

\section{INTRODUCTION}

Inherited retinal diseases (IRDs) are a group of heterogenous degenerative retinal conditions estimated to occur in up to 1 in 1000

\section{Strengths and limitations of this study}

- This is the first study to discern the perspectives of individuals who may be offered gene therapy for inherited retinal disease (IRD) in a standard care setting (outside a clinical trial).

- Recruiting participants with a spectrum of IRD across all ages from multiple sources across Australia, including patient support groups, will allow a comprehensive analysis of participant understanding of and interest in both currently approved and future clinical trials of gene therapies for IRD.

- Collection of utility data (EQ-5D-5L data) will allow health economic calculations for government and insurers who pay for gene therapy.

- The study relies on self-reported diagnosis of IRD.

- The recruitment of self-selecting rather than randomly sampled participants may skew results towards positive views of research given their interest in participating in surveys and/or biases from parents of children affected by IRD.

individuals, ${ }^{12}$ with the major subtype retinitis pigmentosa (RP) occurring in about 1 in 4000 individuals. ${ }^{34}$ IRDs are now the most common cause of legal blindness of adults of working age in Australia ${ }^{5}$ and the UK. ${ }^{6}$ Thus, there is an urgent need for interventions that are aimed at preventing or reversing the ocular manifestations of these genetic conditions.

IRDs predominantly affect the retinal photoreceptors and retinal pigment epithelium (RPE), with variable phenotypes. ${ }^{7}$ Most cases are limited to the eye, but $20 \%-30 \%$ have systemic associations. ${ }^{8}$ In RP rod photoreceptors degenerate first, followed by cones and affected people experience nyctalopia (night blindness), constriction of the visual field and then reduction in visual acuity. Symptoms of RP may appear at birth (Leber congenital 
amaurosis (LCA) phenotype), during childhood (severe early childhood onset retinal dystrophy phenotype) or in adulthood (typical RP phenotype). In cone and cone-rod dystrophy, the cones are affected first, and later the rods may be involved. Affected people may also experience haemeralopia (extreme glare) and loss of central and colour vision. The phenotype may vary between different family members with the same mutation, as exemplified in ABCA4 mutations where a single mutation in family members can result in macular dystrophy, and cone-rod dystrophy phenotypes..$^{910}$

The RPE65 gene (OMIM 180069) is expressed in RPE cells (supporting cells for the photoreceptors), and encodes RPE65 protein, a critical component of the visual cycle and necessary for vitamin A metabolism in cells. ${ }^{11}$ Biallelic mutations in RPE65 lead to degeneration of photoreceptors in humans. ${ }^{12-14}$ Natural history studies show variability in age of onset, degree of severity and disease progression. ${ }^{15} 16$ Biallelic RPE65 mutations are responsible for about $10 \%$ of RP cases with LCA phenotype (LCA type 2 ), and about $2 \%$ of adults with typical RP phenotype (RP 20). ${ }^{17}$

IRDs are genetically diverse, with over 300 responsible genes and loci identified to date in genomic and mitochondrial DNA. ${ }^{18}$ Gene therapy refers to a set of strategies that modify the expression of an individual's genes or repair abnormal genes. ${ }^{19}$ Over 20 gene therapy products have been approved globally for systemic indications, with the two principal approaches including direct in vivo administration of a viral vehicle for gene delivery, and ex vivo therapies generating genetically engineered cells for reintroduction to the patient. ${ }^{20}$ Voretigene neparvovecrzyl (Luxturna) has recently been approved in several jurisdictions for the treatment of biallelic mutations in RPE65 causing retinal dystrophy. ${ }^{21-26}$ Trials of ocular gene therapy for at least 10 IRD are underway. ${ }^{27} 28$ Gene therapy in IRD is thought to have a 'therapeutic window' in that it must be performed while there are residual viable photoreceptors, retinal interneurons and optic nerve. ${ }^{29}$

There is limited data on the potential gains and risks of ocular gene therapy, with results limited to published clinical trials, and no long-term studies available. ${ }^{21-26}$ In general treatments of direct in vivo administration via subretinal injection of a viral vehicle for gene augmentation appear to have an acceptable safety profile. Immunogenicity is low, but inflammation can be triggered, and immunosuppression may be necessary in some cases. Future RNA-based therapies may have less risk of immune reaction. ${ }^{30}$

Currently, there is limited understanding of the potential participant perspective for approved ocular gene therapy. Ganne et a $\vec{l}^{11}$ demonstrated that members of the public have a low level of knowledge of genetic eye disease. Studies to date have focused on participants in early-stage clinical trials of experimental therapies, rather than those receiving approved treatments. The only study of patient-reported outcomes among potential RPE65 gene therapy trial recipients found a high information need and wish to take part in medical decisions. ${ }^{32}$ A 2012 study of potential participants in a choroideraemia gene therapy Phase I trial revealed participant misconceptions of the value of trial participation in safety studies. Participants tended to overestimate treatment effect, underestimate possible risks and show misconceptions about the timing of treatment. ${ }^{33}$ A later study of potential choroideraemia trial participants (NCT02077361) confirmed these findings and noted the value of early-stage published data in influencing treatment decisions and the need to improve postoperative experiences of trial participants. ${ }^{34}$ Similarly, Turriff $e t a l^{35}$ found potential participants in a Phase I/IIa gene therapy trial for $\mathrm{X}$-linked retinoschisis were motivated by therapeutic hope, although the authors considered the individuals to be realistic in their assessments.

There is an evidence-gap for understanding participant views on receiving an approved ocular gene therapy treatment, compared with participating in a clinical trial. Even in standard trials of treatments of retinal conditions, participants may have an incomplete understanding of their rights and the process. ${ }^{36}$ Ocular gene therapy for IRD has the potential to provide significant improvements in quality of life to patients and their families. However, like most medical and surgical procedures, there are associated risks. Hence, it is imperative that researchers and clinicians are aware of patient perspectives on the imminent arrival of approved ocular gene therapies, and use this information to facilitate patient informed consent processes, and to better inform regulatory bodies and reimbursement strategies. Thus, we aim to develop a tool to investigate the knowledge, attitudes and perceptions of the risks and benefits associated with approved and future gene augmentation therapies among people with IRDs. In addition, we aim to assess the quality of life, attitudes towards clinical trials, and vision-related quality of life among this cohort.

\section{METHODS AND ANALYSES Objectives}

The primary objective of this study is to survey Australian patients with an IRD and/or their guardians (for minors) to identify their perceptions and understanding regarding receiving gene therapy treatment for IRD, and to evaluate the effect of key variables, such as quality of life, on perceptions and understanding.

The secondary objective is to develop a novel survey instrument to assess understanding of approved ocular gene therapy (Attitudes to Gene Therapy for the Eye (AGT-Eye) Tool), with instrument calibration and item reduction after survey responses have been received.

\section{Study design}

This will be a structured survey with non-random sampling, primarily administered via internet with a paper-based alternative available as needed. To fulfil the above objectives, we have developed a battery of survey tools, including previously validated questionnaires and 
a newly developed tool, AGT-Eye, survey. The following previously validated survey tools were selected for inclusion in the protocol:

- EQ-5D-5L Questionnaire (a generic health status score $)^{37}$ to assess quality of life, and for use in future cost efficacy and utility calculations using published cost data.

- National Eye Institute Visual Functioning Questionnaire (VFQ-25), ${ }^{38}$ a patient-reported outcome instrument widely used in clinical trials to assess vision-related quality of life. Evidence of the burden of disease will be instrumental for regulatory and funding bodies.

- PACT 22 Clinical Trial Attitudes Scale ${ }^{39}$ to assess attitudes towards clinical trial participation, including therapeutic misconceptions. This will assist in differentiating perceptions of experimental and approved therapies.

Copyright owners of the three validated survey tools have each given permission for their use.

\section{Design of the AGT-Eye Tool}

A three-stage strategy was used in order to develop the items which will be included in the surveys. Communication within focus groups at each stage was implemented by internet video-conferencing and email; as in-person meetings and focus groups were discouraged during the COVID-19 pandemic.

\section{Stage 1: theme generation}

In the first stage an expert working committee consisting of 12 ophthalmologists with expertise in IRD (HM, FKC, JG, TLE, AWH, AK, MH, DM, JR, MS, DAT, JW) followed a Delphi process to identify domains based on their extensive knowledge of IRD gained through involvement with patients in clinical practice and their experience of running a natural history study of IRD. Statements thought to capture the latent traits within these domains were generated in a format to be evaluated against a 5-point Likert scale with responses ranging from Strongly disagree to Strongly agree. These statements were then reviewed independently by an independent multidisciplinary team expert in genetic disease and treatment (RVJ, AGC, GH, AM, BN, IS). Consensus was sought but, where needed, the senior leaders (HM, FKC and JG) arbitrated and made final decisions.

\section{Stage 2: involvement of target population}

A patient engagement advisory committee was recruited from patient support groups, and comprised seven people with IRD, and two parents of minors with IRD. They were provided with a link to the online REDCap database $^{40}$ containing provisional AGT-Eye statements, along with the survey questions, and asked their opinion on the following topics:

- The appropriateness of AGT-Eye statements, including any concerns for respondents' psychological health when answering sensitive questions.
- Additional concepts that they consider relevant which have not been covered in the provisional AGT-Eye statements.

- The accessibility and clarity of the full battery of questionnaires.

- The time required to complete the survey.

- The appropriateness of our proposed recruitment strategies (public and private ophthalmology clinics and patient support organisations).

\section{Stage 3: readability and clarity}

Throughout the process, draft questions were reviewed for readability, clarity and avoidance of duplication by a multidisciplinary committee consisting of researchers with backgrounds in optometry, orthoptics, biostatistics and data management (FO'H, MM, ACZ, NT, LA), all with expertise in retinal disease and online data collection, in addition to the primary investigator (HM). The final 6 domains and 22 questions are shown in table 1.

Responses will be rated on a 5-point Likert scale from 1 Strongly disagree to 5 Strongly agree. Items 4, 6, 7, 8, 12, 16 and 22 will be reversed for consistency of score interpretation. Item 2 will be scored as a mean between 1 and 5 of responses to the nine subitems. Total scores for the 22 AGT-Eye items will range between 22 and 110. The six domains will be scored as weighted means of the component individual items in a range between 1 and 5, and totalled to a range from 6 to 30 . Interpretation of scores is shown in table 2.

Future Stage 4: instrument calibration and item reduction Item response theory methods will be employed to refine the AGT-Eye tool using responses from the full survey. This step will involve item reduction and reassessment of domains if appropriate, as detailed below. After item reduction and reassessment of domains the final AGT-Eye score will be calculated for each respondent to be used in statistical analysis.

\section{Patient and public involvement}

As detailed above, input from people with IRD was sought during stage 2 of AGT-Eye development through a second working group, and their feedback was taken into consideration in the final drafting of the protocol. It is possible that the themes discussed during tool development may prompt these nine people to undertake additional independent research into gene therapy. Therefore, the nine people involved in the working group will be excluded from participating in the final survey, in order to remove a potential source of bias. There was no public involvement in protocol design.

\section{Survey eligibility}

Eligibility criteria includes males and females aged 18 years and above with an IRD, including syndromic forms, or the adult guardian of a person with an IRD who is aged below 18 years. IRDs are defined as retinal disorders caused by an inherited gene mutation resulting in loss of photoreceptor function accompanied by visual 


\begin{tabular}{ll} 
Table 1 & AGT-Eye domains and items \\
\hline & Awareness of treatment \\
\hline 1 & I have good knowledge about gene therapy for \\
inherited retinal diseases. & Sources of information \\
& I have obtained information about gene therapy \\
& treatment from \\
& My ophthalmologist \\
& Other medical or health professional \\
& Registry for example, Australian Inherited Retinal \\
& Disease Register \\
& Research group \\
& Newspapers \\
Internet \\
Social media \\
Patient support group \\
Family/friends
\end{tabular}

\section{Knowledge of clinical trials vs approved} treatment

\begin{tabular}{|c|c|}
\hline \multirow[t]{2}{*}{3} & $\begin{array}{l}\text { I understand the difference between an } \\
\text { experimental treatment provided by a clinical trial } \\
\text { and a treatment that has already been approved } \\
\text { by the Australian government. }\end{array}$ \\
\hline & Timing and method of treatment \\
\hline 4 & $\begin{array}{l}\text { Gene therapy for the eye is suitable at any stage } \\
\text { of a person's life. }\end{array}$ \\
\hline 5 & $\begin{array}{l}\text { Generally, gene therapy for inherited retinal } \\
\text { disease is delivered to both eyes. }\end{array}$ \\
\hline 6 & $\begin{array}{l}\text { Gene therapy for the eye is injected into the blood } \\
\text { stream through the arm. }\end{array}$ \\
\hline \multirow[t]{2}{*}{7} & $\begin{array}{l}\text { Gene therapy and stem cell therapy are the same } \\
\text { treatment. }\end{array}$ \\
\hline & Understanding of outcomes \\
\hline 8 & $\begin{array}{l}\text { Gene therapy for the eye can restore vision back } \\
\text { to normal. }\end{array}$ \\
\hline 9 & $\begin{array}{l}\text { Gene therapy for the eye is a treatment that may } \\
\text { slow down the disease. }\end{array}$ \\
\hline 10 & $\begin{array}{l}\text { Treatment complications to my eyes, such as } \\
\text { permanent blindness, are possible with an } \\
\text { approved gene therapy. }\end{array}$ \\
\hline 11 & $\begin{array}{l}\text { Gene therapy in my eye may have side effects } \\
\text { elsewhere in my body. }\end{array}$ \\
\hline 12 & $\begin{array}{l}\text { Having gene therapy for their eye condition means } \\
\text { a person will not pass on an eye condition to any } \\
\text { children they may have in the future. }\end{array}$ \\
\hline 13 & $\begin{array}{l}\text { I may not be eligible for financial or other } \\
\text { government benefits if my gene therapy for my } \\
\text { eye condition is successful. }\end{array}$ \\
\hline 14 & $\begin{array}{l}\text { Gene therapy for inherited retinal diseases will } \\
\text { require many years of follow-up with my eyecare } \\
\text { practitioner. }\end{array}$ \\
\hline 15 & $\begin{array}{l}\text { Receiving gene therapy for my inherited retinal } \\
\text { disease means I won't be eligible for future } \\
\text { genetic treatments. }\end{array}$ \\
\hline
\end{tabular}

Continued
Table 1 Continued Awareness of treatment

16 I will lose my privacy if I undergo gene therapy, and my data will be in the public domain.

17 If I undergo gene therapy, it will affect my eligibility or terms of conditions in life, disability or health insurance in the future.

Understanding the cost and opportunity cost of treatment

18 The government should pay all costs of my gene therapy.

19 Government subsidy of my treatment would be an effective use of taxpayer money.

20 If gene therapy for my condition was not available in my state I would consider travelling interstate to access it.

$21 \quad$ My private health insurance should pay all out of pocket costs for my gene therapy.

22 I would consider a payment plan for my gene therapy.

Domains (bold) and items designed to measure the attitudes of people with inherited retinal disease towards gene therapy. These domains and items will be revised using item response theory after responses to the survey have been received. Italacised items will be reversed in score calculations for consistency of interpretation. AGT-Eye, Attitudes to Gene Therapy for the Eye.

loss, ${ }^{41}$ and should have been previously diagnosed by an ophthalmologist. No prior confirmation of genotype is required. People who are carriers of IRD mutations but do not display an ocular phenotype will be excluded. People with other retinal conditions with known genetic risk factors (such as age-related macular degeneration) will be excluded in the absence of an ophthalmologistdiagnosed IRD as defined above.

\section{Survey recruitment}

Australian paediatric and adult patients with IRD will be recruited from the Australian Inherited Retinal Disease Registry and DNA Bank (a registry of 4164 IRD-affected participants from 2911 families $),{ }^{42} 43$ Australia's specialist ophthalmic hospitals (Royal Victorian Eye and Ear Hospital and Sydney Eye Hospital), the ophthalmology and clinical genetics departments of the major metropolitan teaching hospitals and the private practices of the authors who are specialists in IRD. All Australian ophthalmologists will be notified through the Royal Australian and New Zealand College of Ophthalmologists and asked to forward an invitation to their eligible patients. Participants will also be recruited through four patient support groups which have given in-principal support: Retina Australia, Vision Australia, Cure Blindness Australia and UsherKids Australia.

Potential participants will be invited to participate by the partners listed above via email or letter, and a social media campaign is planned. Interested people will be 
Table 2 Interpretation of scores on the domains of the questionnaire

\begin{tabular}{lll}
\hline Dimension & Low score & High score \\
\hline Awareness of treatment & $\begin{array}{l}\text { Respondents have low awareness of gene } \\
\text { therapy treatment }\end{array}$ & $\begin{array}{l}\text { Respondents perceive they have high awareness } \\
\text { of gene therapy treatment }\end{array}$ \\
\hline $\begin{array}{l}\text { Sources of information } \\
\text { Knowledge of clinical trials and } \\
\text { approved treatments }\end{array}$ & $\begin{array}{l}\text { Respondents require information } \\
\text { difference between a clinical trial and } \\
\text { approved treatments }\end{array}$ & $\begin{array}{l}\text { Respondents do not require information } \\
\text { difference between a clinical trial and approved } \\
\text { treatments }\end{array}$ \\
\hline Timing and method of treatment & $\begin{array}{l}\text { Respondents have low understanding of } \\
\text { gene therapy process }\end{array}$ & $\begin{array}{l}\text { Respondents have good understanding of gene } \\
\text { therapy process }\end{array}$ \\
Understanding of outcomes & $\begin{array}{l}\text { Respondents have low understanding of } \\
\text { gene therapy outcomes }\end{array}$ & $\begin{array}{l}\text { Respondents have good understanding of gene } \\
\text { therapy outcomes }\end{array}$ \\
Understanding the cost and & $\begin{array}{l}\text { Respondents expect to contribute } \\
\text { personally to the cost of treatment }\end{array}$ & $\begin{array}{l}\text { Respondents expect governments and insurers } \\
\text { to pay for treatment and disability support } \\
\text { services }\end{array}$ \\
\hline Overall score & $\begin{array}{l}\text { Respondents have high information need } \\
\text { regarding gene therapy for IRD }\end{array}$ & $\begin{array}{l}\text { Respondents have sufficient knowledge and } \\
\text { awareness to sign informed consent if they are } \\
\text { offered gene therapy for IRD }\end{array}$ \\
\hline
\end{tabular}

$\mathrm{IRD}$, inherited retinal disease.

directed to the survey webpage to register. Participants will not be compensated for their participation.

\section{Survey sample size}

The number of participants recruited will be limited by the recruitment period (4 months) rather than the number required to statistically evaluate a hypothesis. Based on a population frequency of 1 in 2000 individuals, ${ }^{1}$ Australia's population of patients with IRD is estimated at 16000 . However, many of these people will still be undiagnosed, or may have withdrawn themselves from medical care or patient support organisations (our recruitment streams). Given that responses to internet surveys are typically low, ${ }^{44}$ although unknown in our target population, we estimate gathering responses from 500 participants. It is anticipated that these participants will represent a range of Australians with IRD in terms of age, type and severity of condition, visual function, location of residence and socioeconomic status and comprise approximately $3 \%$ of Australians with IRD. Given this is the first instrument of its kind, the overall and subgroup scores that are required to estimate the statistical power achievable with this sample size are difficult to predict. The primary purpose of this study is to describe the distribution of responses within the population.

\section{Consent}

The consent process will be self-administered via mixedmode approach suitable for visually impaired participants. ${ }^{45}$ Participants completing the online version of the study will read the online plain language statement and an online consent form. Participants will be asked to indicate consent by selecting a YES button. They will then proceed to the survey. Participants who self-complete the paper-based survey will read a plain language statement, sign one consent form and return it by mail, and keep one consent form for their records.

\section{Survey procedure}

We envisage that the majority of participants will enter data directly into the REDCap ${ }^{40}$ platform, which has accessibility functionality (font enlargement and textto-speech facilities). Participants will have the option of providing identifiers (name and email address or telephone number) or remaining anonymous. A small number of older participants who do not have internet availability and/or skills (estimated to be less than 10\%) will complete a paper-based survey and return it with the signed consent form to the researchers by pre-paid mail for entry into the database by study staff. ${ }^{46}$

Email reminders to participate will be sent at 4 weeks by the organisations facilitating recruitment. Participants who have registered and partially completed the survey will receive automated REDCap email reminders at 2 and 4 weeks. Participants who have been mailed a paper-based survey will have a reminder letter mailed at 4 weeks.

\section{Survey}

The paper version of our survey (online supplemental files 1 and 2) shows explanatory wording and the context provided. However, most participants will complete the survey online via REDCap database software. Basic demographic data including age, gender and information relating to socioeconomic status will be collected. Participants will record if they are an affected individual or the parent of an affected child. Self-reported clinical data, such as information about symptoms, history of treatment and perceived barriers to receiving gene therapy will be recorded. Participants will complete the 22 AGT-Eye items, followed by the three previously validated questionnaires. 
The time taken to complete the full survey is estimated up to 1 hour for individuals with low vision.

\section{Participant timeline}

Enrollment will begin early in 2021. The recruitment period will be 4 months. The project is time critical given that Voretigene neparvovec-rzyl was approved in Australia 4 August 2020, and we intend to assess knowledge prior to treatment of the first Australian patient.

\section{Follow-Uup}

No specific follow-up is organised for the participants of the study. However, respondents will be asked if they wish to be contacted with further information on IRDs and upcoming gene therapy options in Australia and if they consent to their deidentified survey data being retained for possible future longitudinal studies (subject to future ethical approval). Respondents will also be provided with contact details for organisations that offer resources for mental health, in case the questions used in the study raise psychological concerns.

\section{Analyses}

The psychometric properties (such as targeting, reliability, consistency, discrimination, dimensionality and differential item functioning) of AGT-Eye will be investigated using item response theory methodology. Item reduction will be performed if appropriate. Participant scores for this instrument will be generated as both a single index value, and according to any identified subscales. Following analysis of the survey responses, items may be reworded or removed before a final version will be recommended for future use. Each of the existing instruments will be scored according to published methods. ${ }^{36-38}$

Descriptive and inferential statistics will be used to investigate the associations between demographics and self-reported clinical data and the scores in the various instruments and the correlation between instruments. Because the AGT-Eye will provide novel data, the distribution of responses will need to be assessed prior to deciding which statistical tests will provide valid inference. Subgroup comparison may be conducted via analysis of variance ( $>2$ groups), Welch's t test or linear regression (2 groups) in the presence of approximately normally distributed AGT-Eye scores. Otherwise, the Kruskal-Wallis test ( $>2$ groups) or the Wilcoxon rank-sum test (2 groups) will be used. Correlation between instruments will be quantified using Spearman's correlation coefficient. Subanalyses will be made of data submitted by persons with IRD compared with parents and guardians of people under the age of 18 years.

A narrative comparison between responses in this cohort and published findings from gene therapy clinical trial participants with eye conditions and other systemic and neurological conditions, such as Huntington's disease, will be made. Huntington's disease has been chosen as a comparator with IRD as both are untreatable neurodegenerative conditions. However, it should be noted that the former is a fatal condition, whereas IRDs lead to an isolated sensory loss, with no risk to life. As such, we will consider the different risk/benefit ratios that patients will need to consider, and the underlying psychological aspects to the two diagnoses. To our knowledge, there is no better comparator-we have not seen studies investigating recently approved non-gene therapies for IRD, for example.

\section{Data collection, management and privacy}

Deidentified data for this study will be collected using REDCap, a secure web application for building and managing online surveys and databases. ${ }^{39}$ REDCap includes a full audit trail and specified user-based privileges. Access to study data in REDCap will be restricted to the members of the study team by username and password and two-factor authentication. User access rights will enforce restricted viewing of Protected Health Information. Data will be accessible to administrators only as deidentified read-only data. Only deidentified data will be permitted to be exported for the purposes of analysis and reporting.

The REDCap platform consists of a MariaDB relational database and a web server. These servers are in a physically secure location on premise at the Centre for Eye Research Australia and managed by the CERA Information Technology team. Both REDCap and MariaDB are widely used, reliable and well-supported systems.

Participants will have the option to choose to provide their name and contact details, and allow their survey results to be identifiable (for future follow-up). This identifiable data will only be available to a limited number of researchers (as specified in our ethics approval).

Storage and destruction of data are compliant with the Australian Privacy Principles ${ }^{47}$ and the Australian National Statement on Ethical Conduct in Human Research. ${ }^{48}$ Intermittent random audit of data quality will be performed by the principal investigator, and governance procedures will be carried out by the Centre for Eye Research Australia.

\section{ETHICS AND DISSEMINATION \\ Ethical review}

Formal ethical approval has been granted by the Human Research Ethics Committee of the University of Melbourne (\#2057534). All procedures are in accordance with the ethical standards of the Helsinki Declaration of 1975 as revised in $2014^{49}$ and with Australian National Statement on Ethical Conduct in Human Research. ${ }^{47}$ All participants will provide consent after being informed of the nature of the study, regardless of survey administration method.

\section{Dissemination}

The study results will be disseminated through scientific publications in peer-reviewed journals and presentations in relevant national and international conferences. 
In addition, deidentified reports of aggregate data and findings will be provided to participants, and presentations at meetings will be provided to Retina Australia, Vision Australia, Cure Blindness Australia and UsherKids Australia. The patient engagement advisory committee will also assist in result dissemination. The standardised checklists such as those from the Strengthening the Reporting of Observational Studies in Epidemiology ${ }^{50}$ guidelines and relevant items from the Consolidated criteria for Reporting Qualitative studies ${ }^{51}$ checklist will be used to ensure that all relevant aspects of study design and data collection are addressed.

\section{Data sharing, access and release}

The deidentified dataset that supports the findings of this study will be made available on reasonable request, to appropriate researchers, subject to approval of an ethics amendment by the relevant Human Ethics Research committee. Requests for data access should be directed to the corresponding author, HGM. Data will be available beginning at 6 months after and ending 7 years following article publication.

\section{DISCUSSION}

IRD is now the most common cause of blindness in working age adults in Australia ${ }^{5}$ and the $\mathrm{UK}^{6}{ }^{6}$ and likely in other developed countries. Aside from the limited evidence that some nutritional supplements can delay progression, for example, Vitamin A supplementation for $\mathrm{RP}^{52}$ there have been no treatments until 2017 when voretigene neparvovec-rzyl (Luxturna) became the first USA Food and Drug Administration-approved treatment for the very rare RPE65 mutations causing congenital and adult-onset IRD. Previous studies have demonstrated that potential gene therapy recipients lack information and have misconceptions regarding the value of trial participation and the risks of treatment. ${ }^{31-36}$ There is no information on the perspectives of persons with RPE65 gene mutations who may be eligible for this approved treatment (as distinct from participating in a clinical trial), or from other persons with IRD who may be eligible for future treatments. This study aims to fill this evidence-gap.

The project is significant in that it will:

1. Validate the first questionnaire regarding participant understanding of approved gene therapy (as distinct from clinical trials) for any indication.

2. By recruiting participants from multiple sources across Australia, including patient support groups, this project will allow a comprehensive analysis of participants' understanding of and interest in both currently approved gene therapy and future clinical trials of new gene therapies for IRDs and a comparison between how approved gene therapy and clinical trials are viewed.

3. Collect quality of life data (EQ-5D-5L, VFQ-25) ${ }^{37} 38$ which will assist health economic calculations for government and insurers who pay for gene therapy.
4. Provide the opportunity to undertake future follow-up surveys, including stratification of data from those who undertake gene therapy and those who decline gene therapy (subject to patient consent for data retention, and future ethics approval), and

5. Allow further collaboration with patient support groups and the patient community, necessary in planning research in rare conditions. ${ }^{53}$

Potential limitations include lack of pilot data, uncertainty around sample size planning, selection bias, self-reporting of data with regard to IRD diagnosis and symptoms and misdiagnoses by ophthalmologists. Discrepancy in quality of life reporting between children and their parents/guardians is well recognised. ${ }^{54}$ To address this, we will perform subanalyses separately on people with an IRD, and the parents/guardians of children. Although genetic testing in IRD is now regarded as the standard of care in Australia, ${ }^{41}$ the majority of patients may not have a genetic diagnosis of their condition. Data capture via an internet-survey, as compared with focus groups for example, may limit the study by low response rate ${ }^{44}$ and reliance on information technology to survey a group of participants who may have low vision. We have sought to overcome low vision limitation by the option of hard copies of the survey to those who request it. The conventional utility measurements (EQ-5D-5L ${ }^{37}$ and VFQ-2 $5^{38}$ ) used may have limitations in this patient group.

In summary, the results of this study will delineate the perspectives of potential ocular gene therapy patients in Australia, critically timed to coincide with approval of the first gene therapy for IRD in Australia, provide a foundation methodology for future studies and generate data for future cost utility measures for this new and exciting treatment option.

\section{Author affiliations}

${ }^{1}$ Centre for Eye Research Australia Ltd, The University of Melbourne, East Melbourne, Victoria, Australia

${ }^{2}$ Centre for Ophthalmology and Visual Science, Lions Eye Institute, University of Western Australia, Nedlands, Western Australia, Australia

${ }^{3}$ Department of Ophthalmology, Royal Perth Hospital, Perth, Western Australia, Australia

${ }^{4}$ Department of Ophthalmology, The University of Sydney, Sydney, New South Wales, Australia

${ }^{5}$ Save Sight Institute, Sydney, New South Wales, Australia

${ }^{6}$ Children's Medical Research Institute, University of Sydney, Sydney, New South Wales, Australia

${ }^{7}$ The Australian Inherited Retinal Disease Registry and DNA Bank, Perth, Western Australia, Australia

${ }^{8}$ Department of Surgery (Ophthalmology), The University of Melbourne, Melbourne, Victoria, Australia

${ }^{9}$ Centre for Epidemiology and Biostatistics, University of Melbourne, Carlton 3053, Victoria, Australia

${ }^{10}$ Royal Victorian Eye and Ear Hospital, East Melbourne, Victoria, Australia

\section{Twitter Alexis Ceecee Britten-Jones @alexisceecee}

Collaborators Australian Ocular Gene Therapy Group: Anai Gonzalez Cordero, Thomas L Edwards, Alex W Hewitt, Gladys Ho, Michael Hogden, Anthony Kwan, Tina Lamey, Alan Ma, David Mackey, Keith R Martin, Terri McLaren, Benjamin Nash, Jon Ruddle, Matthew Simunovic, Ingrid Sinnerbrink, Deepa Ajay Taranath, Jen Thompson and Jaclyn White. 
Contributors HM is the Principal Investigator and conceived the project, drafted the first draft of the AGT-Eye survey and was primary author of this manuscript. She is a guarantor. FKC and JG assisted in protocol development and editing of the manuscript. JDR assisted in protocol development and editing of the manuscript, and also helped with the recruitment strategy (as Lead of the AIRDR). RJ assisted in coordinating multidisciplinary team input and in protocol development. NT, FO'H and $\mathrm{ACZ}$ assisted in protocol development, REDCap database construction and editing of the manuscript. MM assisted in protocol development, REDCap database construction and statistical expertise. LA assisted in protocol development, ethics applications, project management and editing of the manuscript. The members of the Australian Ocular Gene Therapy Group all assisted in AGT-Eye protocol development.

Funding This work was supported by a Retina Australia medical research grant (to HM, FC, JG and LA) for 2021, grant not numbered. Researchers were also supported by an Australian National Health and Medical Research Council Centre of Research Excellence grant (GNT1116360: DM, FKC), Fellowships (MRF1142962: FKC and MRF1151055: LNA), and Ideas Grant (FKC GNT1188694). Centre for Eye Research Australia receives support from the Victorian Government through its Operational Infrastructure Support ProgramProgramme.

Competing interests $\mathrm{HM}, \mathrm{FKC}$ and RJ are members of the Australian Voretigene Expert Advisory Panel for Novartis.

Patient consent for publication Not required.

Provenance and peer review Not commissioned; externally peer reviewed.

Supplemental material This content has been supplied by the author(s). It has not been vetted by BMJ Publishing Group Limited (BMJ) and may not have been peer-reviewed. Any opinions or recommendations discussed are solely those of the author(s) and are not endorsed by BMJ. BMJ disclaims all liability and responsibility arising from any reliance placed on the content. Where the content includes any translated material, BMJ does not warrant the accuracy and reliability of the translations (including but not limited to local regulations, clinical guidelines, terminology, drug names and drug dosages), and is not responsible for any error and/or omissions arising from translation and adaptation or otherwise.

Open access This is an open access article distributed in accordance with the Creative Commons Attribution Non Commercial (CC BY-NC 4.0) license, which permits others to distribute, remix, adapt, build upon this work non-commercially, and license their derivative works on different terms, provided the original work is properly cited, appropriate credit is given, any changes made indicated, and the use is non-commercial. See: http://creativecommons.org/licenses/by-nc/4.0/.

\section{ORCID iDs}

Heather G Mack http://orcid.org/0000-0001-9756-1098

Alexis Ceecee Britten-Jones http://orcid.org/0000-0002-1101-2870

Myra McGuinness http://orcid.org/0000-0002-5422-040X

\section{REFERENCES}

1 Rattner A, Sun $\mathrm{H}$, Nathans J. Molecular genetics of human retinal disease. Annu Rev Genet 1999;33:89-131.

2 Hanany M, Rivolta C, Sharon D. Worldwide carrier frequency and genetic prevalence of autosomal recessive inherited retinal diseases. Proc Natl Acad Sci U S A 2020;117:2710-6.

3 Haim M. Epidemiology of retinitis pigmentosa in Denmark. Acta Ophthalmol Scand Suppl 2002;233:1-34.

4 Hamel C. Retinitis pigmentosa. Orphanet J Rare Dis 2006;1:40.

5 Crewe JM, Morlet N, Morgan WH, et al. Mortality and hospital morbidity of working-age blind. Br J Ophthalmol 2013;97:1579-85.

6 Liew G, Michaelides M, Bunce C. A comparison of the causes of blindness certifications in England and Wales in working age adults (16-64 years), 1999-2000 with 2009-2010. BMJ Open2013.

7 Verbakel SK, van Huet RAC, Boon CJF, et al. Non-Syndromic retinitis pigmentosa. Prog Retin Eye Res 2018;66:157-86.

8 Pierrottet CO, Zuntini M, Digiuni M, et al. Syndromic and nonsyndromic forms of retinitis pigmentosa: a comprehensive Italian clinical and molecular study reveals new mutations. Genet Mol Res 2014;13:8815-33.

9 Burke TR, Tsang SH. Allelic and phenotypic heterogeneity in ABCA4 mutations. Ophthalmic Genet 2011;32:165-74.

10 Huang D, Thompson JA, Charng J, et al. Phenotype-Genotype correlations in a pseudodominant Stargardt disease pedigree due to a novel ABCA4 deletion-insertion variant causing a splicing defect. Mol Genet Genomic Med 2020;8:e1259.
11 Palczewski K. Chemistry and biology of the initial steps in vision: the Friedenwald lecture. Invest Ophthalmol Vis Sci 2014;55:6651-72.

12 Marlhens F, Bareil C, Griffoin JM, et al. Mutations in RPE65 cause Leber's congenital amaurosis. Nat Genet 1997;17:139-41.

13 Gu SM, Thompson DA, Srikumari CR, et al. Mutations in RPE65 cause autosomal recessive childhood-onset severe retinal dystrophy. Nat Genet 1997;17:194-7.

14 Weleber RG, Michaelides M, Trzupek KM, et al. The phenotype of severe early childhood onset retinal dystrophy (SECORD) from mutation of RPE65 and differentiation from Leber congenital amaurosis. Invest Ophthalmol Vis Sci 2011;52:292-302.

15 Paunescu K, Wabbels B, Preising MN, et al. Longitudinal and crosssectional study of patients with early-onset severe retinal dystrophy associated with RPE65 mutations. Graefes Arch Clin Exp Ophthalmol 2005;243:417-26.

16 Chung DC, Bertelsen M, Lorenz B, et al. The natural history of inherited retinal dystrophy due to biallelic mutations in the RPE65 gene. Am J Ophthalmol 2019;199:58-70.

17 Morimura H, Fishman GA, Grover SA, et al. Mutations in the RPE65 gene in patients with autosomal recessive retinitis pigmentosa or Leber congenital amaurosis. Proc Natl Acad Sci U S A 1998;95:3088-93.

18 RetNet: summaries of genes and loci causing retinal diseases, 2020. Available: sph.uth.edu/retnet/sum-dis.htm\#A-genes [Accessed 14 Dec 2020].

19 Salzman R, Cook F, Hunt T, et al. Addressing the value of gene therapy and enhancing patient access to transformative treatments. Mol Ther 2018;26:2717-26.

20 Shahryari A, Saghaeian Jazi M, Mohammadi S, et al. Development and clinical translation of Approved gene therapy products for genetic disorders. Front Genet 2019;10:868.

21 Cideciyan AV, Jacobson SG, Beltran WA, et al. Human retinal gene therapy for Leber congenital amaurosis shows advancing retinal degeneration despite enduring visual improvement. Proc Natl Acad Sci U S A 2013;110:E517-25.

22 Bainbridge JWB, Mehat MS, Sundaram V, et al. Long-Term effect of gene therapy on Leber's congenital amaurosis. N Engl J Med 2015;372:1887-97.

23 Russell S, Bennett J, Wellman JA, et al. Efficacy and safety of voretigene neparvovec (AAV2-hRPE65v2) in patients with RPE65mediated inherited retinal dystrophy: a randomised, controlled, openlabel, phase 3 trial. Lancet 2017;390:849-60.

24 Maguire AM, Russell S, Wellman JA, et al. Efficacy, safety, and durability of Voretigene Neparvovec-rzyl in RPE65 MutationAssociated inherited retinal dystrophy. Ophthalmology 2019:126:1273-85

25 Miraldi Utz V, Coussa RG, Antaki F, et al. Gene therapy for RPE65related retinal disease. Ophthalmic Genet 2018;39:671-7.

26 Maguire AM, Bennett J, Aleman EM, et al. Clinical perspective: treating RPE65-Associated retinal dystrophy. Mol Ther 2021;29:442463.

27 Garafalo AV, Cideciyan AV, Héon E, et al. Progress in treating inherited retinal diseases: early subretinal gene therapy clinical trials and candidates for future initiatives. Prog Retin Eye Res 2020;77:100827.

28 Fuller-Carter PI, Basiri H, Harvey AR, et al. Focused update on AAVBased gene therapy clinical trials for inherited retinal degeneration. BioDrugs 2020;34:763-81.

29 Beltran WA, Cideciyan AV, Iwabe S, et al. Successful arrest of photoreceptor and vision loss expands the therapeutic window of retinal gene therapy to later stages of disease. Proc Natl Acad Sci $U$ $S$ A 2015;112:E5844-53.

30 Brenner D, Ludolph AC, Weishaupt JH. Gene specific therapies - the next therapeutic milestone in neurology. Neurol Res Pract 2020;2:25.

31 Ganne P, Garrioch R, Votruba M. Perceptions and understanding of genetics and genetic eye disease and attitudes to genetic testing and gene therapy in a primary eye care setting. Ophthalmic Genet 2015;36:50-7.

32 Nelles M, Stieger K, Preising MN, et al. Shared decision-making, control preferences and psychological well-being in patients with RPE65 deficiency awaiting experimental gene therapy. Ophthalmic Res 2015;54:96-102.

33 Benjaminy S, Macdonald I, Bubela T. "Is a cure in my sight?" Multistakeholder perspectives on phase I choroideremia gene transfer clinical trials. Genet Med 2014;16:379-85.

34 Brooks SP, Benjaminy S, Bubela T. Participant perspectives on a phase I/II ocular gene therapy trial (NCT02077361). Ophthalmic Genet 2019;40:276-81.

35 Turriff A, Blain D, Similuk M, et al. Motivations and decision making processes of men with $\mathrm{X}$-linked retinoschisis considering 
participation in an ocular gene therapy trial. Am J Ophthalmol 2019;204:90-6.

36 Au CP-Y, Fardell N, Williams M, et al. Patient experiences in retinal trials: a cross-sectional study. BMC Ophthalmol 2015;15:80.

37 Herdman M, Gudex C, Lloyd A, et al. Development and preliminary testing of the new five-level version of EQ-5D (EQ-5D-5L). Qual Life Res 2011;20:1727-36.

38 Mangione CM, Lee PP, Gutierrez PR, et al. Development of the 25-item National eye Institute visual function questionnaire. Arch Ophthalmol 2001;119:1050-8.

39 Jenkinson C, Burton JS, Cartwright J, et al. Patient attitudes to clinical trials: development of a questionnaire and results from asthma and cancer patients. Health Expect 2005;8:244-52.

40 Harris PA, Taylor R, Minor BL, et al. The REDCap Consortium: building an international community of software platform partners. $J$ Biomed Inform 2019;95:103208.

41 Grigg J, Jamieson R, Chen F. Guidelines for the management of patients with inherited retinal disease Royal Australian and New Zealand College of Ophthalmologists; 2020. www.ranzco.edu

42 De Roach JN, McLaren TL, Paterson RL, et al. Establishment and evolution of the Australian inherited retinal disease register and DNA bank. Clin Exp Ophthalmol 2013;41:476-83.

43 De Roach JN, McLaren TL, Thompson JA. The Australian inherited retinal disease registry and DNA bank. Tasman Med J 2020;2:60-7.

44 Saleh A, Bista K. Examining factors impacting on-line survey response rates in educational research: perceptions of graduate students. J Multidisciplinary Eval 2017;13:63-74

45 Kaczmirek L, Wolff KG. Survey design for visually impaired and blind people. In: Stephanidis C, ed. Universal access in human computer interaction. Part I, coping with diversity. Berlin: Springer, 2007: 374-81.
46 Choi NG, DiNitto DM, Lee OE, et al. Internet and health information technology use and psychological distress among older adults with self-reported vision impairment: case-control study. J Med Internet Res 2020;22:e17294.

47 Australian Government, Office of the Australian Information Commissioner. Australian privacy principles, 2020. Available: https:// www.oaic.gov.au/privacy/australian-privacy-principles/

48 Australian Government, National Health and Medical Research Council. National statement on ethical conduct in human research 2007. Available: https://www.nhmrc.gov.au/about-us/publications/ national-statement-ethical-conduct-human-research-2007-updated2018

49 General Assembly of the World Medical Association. World Medical association Declaration of Helsinki: ethical principles for medical research involving human subjects. J Am Coll Dent 2014;81:14-18.

50 Vandenbroucke JP, von Elm E, Altman DG, et al. Strengthening the reporting of observational studies in epidemiology (STROBE): explanation and elaboration. Epidemiology 2007;18:805-35.

51 Tong A, Sainsbury P, Craig J. Consolidated criteria for reporting qualitative research (COREQ): a 32-item checklist for interviews and focus groups. Int J Qual Health Care 2007:19:349-57.

52 Berson EL, Rosner B, Sandberg MA, et al. A randomized trial of vitamin $\mathrm{A}$ and vitamin $\mathrm{E}$ supplementation for retinitis pigmentosa. Arch Ophthalmol 1993;111:761-72.

53 Raffai F, Timmis O. Building the patient community. Gene Ther 2017;24:547-50.

54 Eiser C, Varni JW. Health-Related quality of life and symptom reporting: similarities and differences between children and their parents. Eur J Pediatr 2013;172:1299-304. 